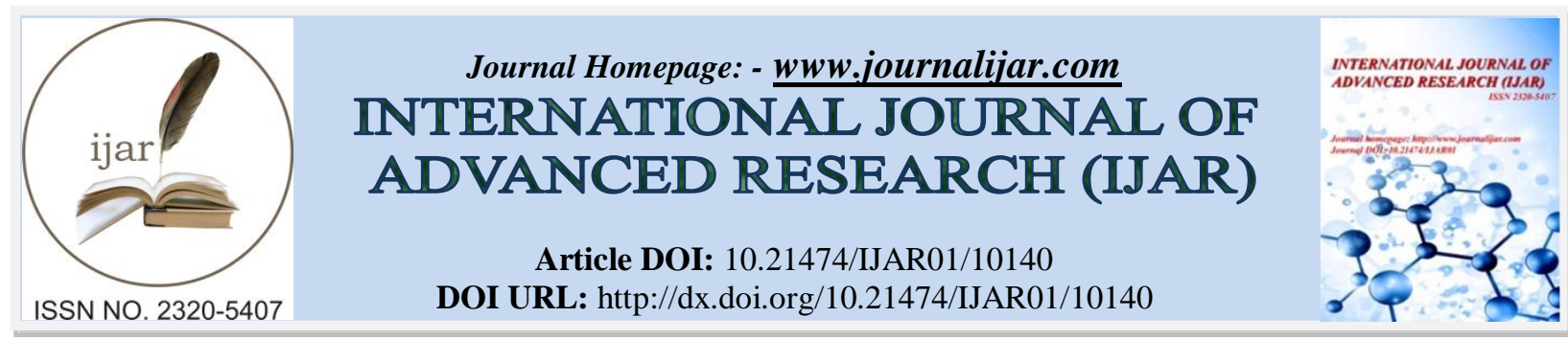

RESEARCH ARTICLE

\title{
QUALITY ENHANCEMENT INITIATIVES AND GIRL CHILD PERFORMANCE IN MATHEMATICS IN SECONDARY SCHOOLS IN KENYA: A CASE STUDY OF KWANZA DIVISION, KENYA.
}

Salome Awinja Simiyu, Simiyu Kefer, Ezine Enos, Ben Malesi, Murunga Joseph, Roes Kisaka, Beatrice Watiti, Leaonard Wekesa, Nicolas Wamalwa, Kellways Nyamanga, Daniel Wamalwa, Mwalo Maurice and Susan Chematui. Med (policy planning and management)Busoga University.

\section{Manuscript Info}

\section{Manuscript History}

Received: 01 October 2019

Final Accepted: 03 November 2019

Published: December 2019

Key words:-

Quality, Enhancement, Persistent, Phenomena, Chi-Square, Proportionate.

\begin{abstract}
The purpose of the study was to investigate the quality enhancement initiatives and girl child performance in Mathematics in Secondary Schools in Kwanza Division of Trans- Nzoia county- Kenya. The problem for investigation was on the phenomenon of persistent poor performance of girl child in mathematics in Kwanza Division. The objectives of the study were: identify the quality initiatives that affect performance in mathematics in secondary schools in Kwanza Division, establish the extent to which quality enhancement initiatives have enhanced mathematics performance of girl child in secondary school in Kwanza division, establish factors affecting the effectiveness of quality enhancement initiatives in enhancing mathematics performance of girl child in secondary school in Kwanza division. The sample size of this study was two hundred and fifty six (256) respondents drawn form a total population of seven hundred and fifty (750) (Krejcie and Morgan 1970). The study used proportionate stratified sampling and simple random sampling techniques. We used questionnaires to enlist information from the study respondents. Data was analyzed using Pearson's Chi-square test to compare significance of opinion of respondents about relationships of study variables. The findings reveal a considerable influence of quality enhancement initiatives on performance of the girl child in mathematics in Kwanza Division. The study revealed that the performance of the girl child in mathematics in secondary schools can be enhanced through these initiatives. It is thus recommended that most of the secondary schools and authorities ought to focus on improving on the quality enhancement initiatives.
\end{abstract}

Copy Right, IJAR, 2019,. All rights reserved.

\section{Introduction:-}

In this chapter the framework is about the study of the quality enhancement initiatives and the performance of the girl child in mathematics in secondary schools in Kwanza Division of Trans-Nzoia County. The following aspects are covered: - the background, the historical background, theoretical background, the conceptual background the contextual background, the general and specific objectives, the research questions, the scope and the significance of the study. 


\section{Background to the Study:}

The study is concerned with the phenomenon of quality enhancement initiatives and girl child performance in Mathematics in secondary schools in Kwanza Division, Kenya. The phenomenon of quality enhancement initiatives worldwide has attracted a lot of attention in many countries over its nature, content, relevance and achievement in relation to performance in mathematics of girl child in learning institutions and in all aspect of life like marketing, industry, engineering, production and the consumer society. There have been many studies that seek to examine the issue of the quality enhancement initiatives on the performance of girls in Mathematics in Secondary Schools and their findings have pointed out on issues to do with single sex streams, the book policy and attendance of seminars by both students and teachers and the role of the parents, their income bracket how much they assist their children with their homework. Chen, Lee, \& Stevenson, (2006) compared students' achievement and their parents' involvement in China and the USA and found that Chinese parents had higher expectations of their children performance and spent more time helping their children with school homework than the USA. Due to this involvement they tended to present better results. Females have demonstrated that they are equally capable of learning and mastering mathematical concepts and knowledge as their male counterparts (Meinholt \& Murray, 2009). However, results of standardized assessments measuring mathematics performance by gender are mixed. In some specific mathematical content areas males outperform female peers (Mullis, Martin, \& Foy, 2008). In other instances, females complete comparable levels of mathematics coursework as their male peers and attain degrees in mathematics at rates similar to males (Ingels \& Dalton, 2008). Further insights are provided by examining statistical trends related to gender differences in mathematics performance in relation to studies that identify environmental factors that influence the motivation and performance of females related to mathematics achievement (Kiefer \& Sekaquaptewa, 2007).

Achievement in different school subjects is determined by factors within the school milieu and within student variables. Research studies on achievement variations across schools, states and nations have examined important components of school system such as learning resources, class size, teaching- learning practices, monitoring and evaluation practices and teacher competency, and have concluded these factors as correlates of achievement. For example Samilre \& Kongsh (2005) pointed that school based factors like class size, number of minority students in the class, number of algebra units taken, number of graduate courses taken by teacher in the subject she teaches most frequently and home- based factors socio- economic status, home language, time spent on home work, family composition, level of parent involvement are correlated with success of every child. Lavree \& Kelsvre (2008) reported that a student's home language is central to success in school, particularly when it is related to the level of parental education. According to Lorenz \& Legazpi (2009) income level of a student's family is highly correlated with academic success in school. A study by Portes \& McLord (2006) identified an overwhelming relationship between race /ethnicity and academic achievement. Gender difference in reading and Mathematics was reported by (Pollyann \& Onwuegebuzie, 2001).

A study that examined the effect of homework time specifically in mathematics achievement by (Pizdex \& Menious 2002) found that increasing accuracy of parent awareness of their children mathematical skill may be a sensible first step toward the poor mathematic performance of children, participation of both parents and teachers to help with homework was found to increase the depth and quality of learning (Hatch, 2008). Providing great motivation, responsibility sense of purpose and confidence all the factors could contribute to increase student achievement with homework completion. These studies do not address the phenomenon in mathematics in Kenya, but also worldwide. Universal Declaration of Human Rights of 1948 identified education as a fundamental human right. Kenya is signatory to various international protocols such as Education for All (EFA) passed in Jomtien, Thailand in 1990 and the World Education Forum in Dakar Senegal in 2000. This was why the Government of Kenya (GOK) has been providing Free Primary Education (FPE) and Free Secondary Education (FSE) since 2003 and 2008 respectively. Despite the efforts made in the education sector countrywide over the last ten years, female students' performance in the district has not improved much but has been very low. In Africa, provision of education was key development agenda at attainment of independence. During the Addis Ababa Conference of 1961 by the African Heads of States, expansion of education system was out of the mainly discussed issues (Sinfuna \& Mangarety, 2006).

Discussions on the parents influence on the girl child performance on mathematics have been going on throughout the world and even within continent of Africa. This is due to the focus on Kenya's vision 2030, which aims at industrialization and also performance on the girl child on mathematics and science. The Japanese government has come up with the SMASE project with aim of Strengthening Mathematics and Science in Education whose aim is to 
enhance the learning of mathematics and science in Kenya. Studies on gender gaps in achievement by Guarrenga \& Kaufman (2005) concluded that girls score lower than boys on standardized test of mathematics. They continue to argue that such gaps are real and very significant and cannot be trivialized as test scores determine to higher training and by extension future success. This argument is supported by the work of Nelson (2010) who found out that in mathematically related fields. Campbell \& Moganees (2005) looks at parents as playing a crucial role in their daughters' mathematics and science education. Analysis is made of how parents can encourage their daughters in mathematics and science. She suggests that parents talk to their daughters about the importance and its necessity in certain careers. Parents are encouraged to foster positive attitude in their daughter towards mathematics and science. Quality enhancement initiatives among other contributions to mathematics performance of girl child are critical to the organization. In the Kenyan scenario, the application of the theories is relevant to the areas of study. It is based on the above situation that we sort to determine several factors that impact on mathematics performance of girl child. These factors include the fact that the Kenyan government interventions towards good performance in mathematics and science have been witnessed through the ministry of education efforts through the establishment of strengthening mathematics and science in secondary schools education (SMASSE) programs. Through these female mathematics and science teachers have been taxed with encouraging girls to excel through organized talks to various girls in secondary schools.

Apparently, the Japanese Government in collaboration with Kenyan Government turned its attention to support Kenya government efforts in enhancing good performance in mathematics and sciences through manpower recruitment and training, institutional organization and increased stakeholders' participation to enhance good performance. However quality enhancement initiatives are singled out as key factors in relation to performance of mathematics of girl child. Maslow's 1943 theory of the hierarchy of needs, deciphers that human beings have specific needs that ought to be met. There are given needs namely psychological, sex, hunger, safety, security, stability and protection, love and belongings, self esteem and self actualization. The key argument is that when the lower needs remains unmet the higher needs cannot be fulfilled. The theory bears significance to the area of study because meeting the basic survival needs like security, self esteem and self actualization are important requirement to the area of study. It would be established that without realization of higher needs, needs of girls including mathematics effective performance cannot be attained. The theory seeks to establish the truth that girl child who have not been provided with basic needs and mathematics scholastic materials will be discouraged and hence leads to poor performance in mathematics. The other contributor to the quality enhancement initiatives theories are, (Maddi \& KObasa, 2001) who state that there is negative relationship between individual scores in mathematics and anxiety. These factors are important to the researcher to access how quality enhancement initiatives factors will influence girl child mathematics performance.

Garry (2005) observed that the scores of mathematics anxiety indicate that girls have experienced more level of mathematical anxiety than boys hence affect negatively their performance. This theory will be relevant to the study because he observed that the scores of mathematics and anxiety indicates that girls have experienced more level of mathematics anxiety than boys hence affect negatively their performance. Thus quality enhancement initiatives improved results due to establishment of single sex streams, book policy and more attendance of seminars by teachers and girl's students hence encouraged to influence girl child performance in mathematics. Kamau (2001) supports this view that girls are "connected" thinkers who require exploration of content and relationships when doing mathematics. This view is also shared by Haedey (2009) who says that on the other hand that girls prefer cooperative, supportive working environment, while their male counterparts opt for competitive and pressurized environment. Lytton \& Roney (2001) observed that there is evidence indicating that parents more closely monitor girls' progress than that of boys, correct girls' mistake more than those of boys and make decisions for girls than for boys. Parents also see girls' performance in mathematics due to their effort but see boys' performance in this area as due to their abilities (Eccles \& Harol, 2008). In this case girl child will compare their own efforts and rewards from parents with those of their counterparts. These comparisons are likely to influence students' perception of their own status. In the scenario in Kenya, the girl child performance in mathematics in secondary school wants more so with schools whose parents are of low economic status especially in rural areas. The above move would make the equity theories relevant to the area study.

Mado \& Kobassa (2002) observe that there is negative relationship between individual hardness scores and mathematics anxiety. Ashcraft \& Faust (2004) on the other hand, whereas the schooling experience of boys and girls is different, current studies have concluded that there is no significance gender difference with respect to academic achievement and general abilities (Lingard 2005). These factors are important for the researcher to access how 
parents' factors affect girl child mathematics performance. Garry (2005) observed that the scores of mathematics anxiety indicate that girls have experienced more level of mathematical anxiety than boys hence affect negatively their performance. Armstrong (2009) defines a girl as a female child, from birth to full growth of 18 years of age, but unmarried. According to Garry (2005); mathematics is as the science of quantity. Eccles \& Harol (2008) on the other hand define mathematics as a science that draws necessary conclusions. According to Armstrong (2009) mathematics is symbolic logic. Armstrong (2009) defines performance as the accomplishment of a given task measured against present known standards of accuracy, completeness, cost and speed. In a contrast, performance is deemed to be the fulfillment of an obligation in a manner that releases the performance from all liabilities under the contract. Meleord \& Schauffler, (2001) defines performance standards as the knowledge and skills that students are to perform at various stages of educational development (performance descriptors) and the performance expectations (performance levels and assessment tasks) for student work at each of the stages.

The phenomenon of quality enhancement initiative is based on characteristics like socio-economic, politics, geographical location, school mapping, and gender status and enrollment figures. The phenomena of quality enhancement initiatives and girl child performance in mathematics in secondary schools have received little attention from the government in Kenya. There is need to investigate the intervention of the government regarding the performance of girl child in mathematics in secondary schools. The girl child performance in mathematics is still a challenge which ideally forms four decisions to make the study in Kwanza Division in Kenya. The Ministry of Education Science and Technology Report, (2008) revealed that the government does not have any clear policy on girl child mathematics performance. Most secondary schools in Kwanza Division are day public mixed secondary schools. High rate of poverty among residents of Kwanza Division have been listed as a major problem in the region. The Division economy depends mainly on small holder subsistence agriculture which is hampered by poor rainfall pattern. The secondary school going age group had 17,678 students in 1999 which represent $11.8 \%$ of the total population in Kwanza District where Kwanza Division is the biggest division among the three. The projected population at the start of 2008 plan period was 23, 437 and this has risen to 35,979 in 2013 at the end of the plan period. Kwanza District is divided into three divisions. The quoted population represents $75 \%$ of Kwanza division while the remaining 25\% represents Endebess division and Kaisagat division. The population of enrollment in secondary schools represents an interesting trend as per 2013. Form 1 enrollment $60 \%$ are girls and $40 \%$ are boys, in form 11 enrollment, 50\% are girls and 50\% are boys, in form 111 enrollment, $40 \%$ girls and $60 \%$ boys and form $1 \mathrm{~V}$ enrollment, $70 \%$ boys and 30\% girls. Therefore from the above analysis out of the total population of 35, 979 students, 11,500 are girls (35\%) and 24, 479 are boys (65\%). The enrollment in form 1 is higher for girls than boys and reduces as they proceed to form IV. The Kenya national examination council statistics 2010 show the following form four Kenya certificate of secondary education. The schools that were nurtured well by quality enhancement policies registered superior results i.e. Alliance boys had a mean score 10.8, Mang'u 10.07, Friends school Kamusinga 10.05 and Goseta 8.0. The schools with low quality enhancement factor are Kwanza Friends 6.0, Boma 5.2, Chisare 3.2, and Kwanza girl 4.1 among others. The study will investigate the effects of parents' economic factors on girl child performance in mathematics in secondary schools in Kwanza Division.

\section{Statement of the Problem:}

Despite the efforts made in the education sector countrywide over the last ten years, female students' performance in the district has not improved much but has been very low. According to Kenya National Examination Council (2011) report the following trend in performance in mathematics is noted; mathematics is a compulsory subject in computation of the mean score for a candidate and therefore a candidate must pass in order to achieve a grade that provide entry to public university. In the year 2011 mathematics performance by girls was poor compared to boys and this translates into low enrolment in the universities for girls, as all students admitted in the universities must have passed mathematics. Statistics from the Ministry of Education reveal that female students comprised 30.5\% of the total enrollment of 40,613 students at the five public universities in the 1998/ 99 academic years (Hatch, 2008). Analysis of student enrollment in public universities confirmed that relatively few women are enrolled in science courses and especially engineering (Garry, 2005). The District Kenya Certificate of Secondary Examination (2011) results analysis, revealed that the girl child performed poorly in mathematics. According to Kwanza District in Kenya form four mathematics examination analysis from 2009- 2011 shows there is observable poor performance/ decline in performance of girl child in mathematics as indicated by form four results (see table below). 
Table 1:- 1.0 Performance in Mathematics of two mixed Secondary Schools in Kenya.

\begin{tabular}{|c|c|c|c|c|c|c|c|c|c|c|c|c|}
\hline \multicolumn{7}{|c|}{ NAMANJALALA } & \multicolumn{6}{|c|}{ ST. PETERS'- KAPOMBOI } \\
\hline \multicolumn{4}{|l|}{ BOYS } & \multicolumn{3}{|c|}{ GIRLS } & \multicolumn{3}{|c|}{ BOYS } & \multicolumn{3}{|c|}{ GIRLS } \\
\hline & 2009 & 2011 & 2012 & 009 & 010 & 011 & 009 & 010 & 011 & 09 & 010 & 011 \\
\hline A & 3 & 1 & 0 & & & & & & & & & \\
\hline A- & 5 & 4 & 9 & & & & & & & & & \\
\hline $\mathrm{B}+$ & 4 & 2 & 4 & & & & 1 & & & & & \\
\hline $\mathrm{B}$ & 3 & 2 & 1 & & & & 2 & 1 & & & & \\
\hline B- & 3 & 5 & 3 & 1 & & 1 & 1 & 2 & 1 & & & \\
\hline $\mathrm{C}+$ & 7 & 8 & 6 & 4 & 6 & 5 & 4 & 3 & 1 & & & \\
\hline $\mathrm{C}$ & 6 & 4 & 3 & 5 & 4 & 4 & 3 & 4 & 3 & & 1 & \\
\hline $\mathrm{C}-$ & 10 & 6 & 5 & 3 & 3 & 2 & 3 & 5 & 4 & 2 & 1 & 1 \\
\hline D+ & 4 & 3 & 4 & 4 & 2 & 3 & 1 & 2 & 4 & 2 & 3 & 4 \\
\hline D & 4 & 4 & 5 & 4 & 6 & 5 & 1 & 1 & 4 & 4 & 1 & 3 \\
\hline D- & 2 & 1 & 1 & 9 & 6 & 8 & 0 & 1 & 3 & 3 & 4 & 2 \\
\hline $\mathrm{E}$ & 1 & 2 & 1 & 6 & 4 & 5 & 4 & 5 & 5 & 6 & 5 & 7 \\
\hline Total & 51 & 42 & 41 & 36 & 31 & 33 & 20 & 20 & 21 & 17 & 15 & 17 \\
\hline $\begin{array}{l}\text { Mean } \\
\text { score }\end{array}$ & 6.8 & 6.33 & 4.09 & 3.6 & 4.03 & 3.6 & 5.4 & 4.65 & 3.9 & 2.47 & 2.4 & 2.7 \\
\hline $\begin{array}{l}\text { MEAN } \\
\text { GRADE }\end{array}$ & $\mathrm{C}+$ & $\mathrm{C}$ & $\mathrm{D}+$ & $\mathrm{D}+$ & $\mathrm{D}+$ & D+ & $\mathrm{C}$ & C- & $\mathrm{D}+$ & D- & D- & $\mathrm{D}$ \\
\hline
\end{tabular}

Table 2:- 1.1. Performance in mathematics of two mixed secondary schools in kenya.

\begin{tabular}{|c|c|c|c|c|c|c|c|c|c|c|c|c|}
\hline \multicolumn{7}{|c|}{ ST. MATHEWS'- CHEPTANDAN } & \multicolumn{6}{|c|}{ CHISARE } \\
\hline \multicolumn{4}{|c|}{ BOYS } & \multicolumn{3}{|c|}{ GIRLS } & \multicolumn{3}{|c|}{ BOYS } & \multicolumn{3}{|c|}{ GIRLS } \\
\hline & 2009 & 2010 & 2011 & 009 & 010 & 011 & 009 & 010 & 011 & 009 & 010 & 011 \\
\hline A & & & & & & & 1 & 0 & 2 & & & \\
\hline A- & & & 1 & & & & 1 & 2 & 1 & & & \\
\hline $\mathrm{B}+$ & & 1 & 0 & & & & 2 & 3 & 2 & 1 & 0 & 0 \\
\hline B & 1 & 0 & 1 & & & & 3 & 1 & 0 & 2 & 0 & 0 \\
\hline B- & 3 & 2 & 1 & 0 & 1 & 0 & 0 & 4 & 1 & 0 & 2 & 2 \\
\hline $\mathrm{C}+$ & 5 & 3 & 4 & 1 & 2 & 4 & 5 & 3 & 5 & 1 & 1 & 1 \\
\hline $\mathrm{C}$ & 3 & 5 & 3 & 2 & 1 & 1 & 3 & 1 & 2 & 1 & 3 & 1 \\
\hline C- & 4 & 2 & 3 & 2 & 2 & 1 & 4 & 1 & 2 & 2 & 0 & 1 \\
\hline D+ & 2 & 5 & 4 & 3 & 1 & 3 & 1 & 2 & 3 & 3 & 4 & 4 \\
\hline $\mathrm{D}$ & 2 & 4 & 6 & 3 & 4 & 4 & 2 & 1 & 2 & 1 & 3 & 4 \\
\hline D- & 2 & 3 & 2 & 4 & 1 & 2 & 1 & 3 & 1 & 4 & 4 & 2 \\
\hline$E$ & 3 & 5 & 4 & 5 & 8 & 5 & 4 & 3 & 3 & 7 & 5 & 6 \\
\hline Total & 25 & 30 & 29 & 20 & 22 & 20 & 27 & 24 & 24 & 22 & 22 & 21 \\
\hline $\begin{array}{l}\text { Mean } \\
\text { score }\end{array}$ & 5.08 & 4.33 & 4.52 & 3.15 & 2.91 & 3.6 & 5.8 & 6.04 & 5.9 & 3.68 & 3.59 & 3.42 \\
\hline $\begin{array}{l}\text { Mean } \\
\text { grade }\end{array}$ & C- & D+ & C- & $\mathrm{D}$ & $\mathrm{D}$ & D+ & C & $\mathrm{C}$ & $\mathrm{C}$ & D+ & $\mathrm{D}+$ & $\mathrm{D}$ \\
\hline
\end{tabular}

Source: Kwanza District KCSE analysis 2011

Meanwhile, the Kenyan government in collaboration with Japan government has responded in strengthening mathematics and sciences in secondary schools through the Ministry of Education, Science and Technology in Kenya (2004), towards increased opportunities for further training of teachers to improve performance in 
mathematics and sciences. The objective also includes enhancing performance of girl child in mathematics. The Ministry of Education has also incorporated administration in the SMASSE programme sensitizing parents to provide scholastic materials and encourage girl child to have positive attitudes towards mathematics and science. The foregoing evidence available shows that a lot has been done to enhance girl child performance in mathematics. Nevertheless there is persistent low performance in mathematics compared to boys in Kwanza division in Kenya. Its observable that parents economic factor is lacking in the efforts to realize good results in mathematics. This study therefore sought to enquire into the phenomena of persistent poor performance of girl child in mathematics in Kwanza Division in Kenya.

\section{Objectives To The Study:}

1. To identify the quality initiatives that affect performance in mathematics in secondary schools in Kwanza Division.

2. To establish the extent to which quality enhancement initiatives have enhanced mathematics performance of girl child in secondary school in Kwanza division.

3. To establish factors affecting the effectiveness of quality enhancement initiatives in enhancing mathematics performance of girl child in secondary school in Kwanza division.

\section{Research questions:}

1. What are the quality enhancement initiatives affecting girl child performance in mathematics in secondary school in Kwanza division?

2. To what extent have quality enhancement initiatives affected mathematics performance of girl child in secondary school in Kwanza division?

3. Which factors affect the effectiveness of quality enhancement initiatives in enhancing mathematics performance of girl child in secondary schools in Kwanza division?

\section{Significance of the study:}

The study may be significant to parents who expect not just excellent performance but also responsible men and women outside school. It may also interest undergraduates and prospective students who may wish to pursue excellence in their chosen academic career. This study would serve to bridge the gap in knowledge, regarding the relationship between the quality enhancement initiatives and the girl child performance in mathematics in secondary schools in Kwanza division. It would also enhance the existing literature for the benefit of policy makers, scholars and other stakeholder in Kenya including the District Education Board and Kwanza Division Development Committee in mobilizing and creating awareness of quality enhancement initiatives in enhancing the performance of girl child in mathematics in secondary schools in Kwanza division. This study would also serve as a reference material for scholar education in Busoga University and institutions of higher learning, finally the study would reveal other areas that may need further research.

\section{Review Of Related Literature: Introduction:}

This chapter reviews the literature related to the subject under investigation in order to shed light on the subject and also provide a framework for investigation. There is an introduction that sets the overall framework, theoretical framework, the conceptual framework showing the nature of variables at work, the themes related to the literature review mainly to establish the quality enhancement initiatives affecting mathematics performance of girl child in secondary schools, the extent to which parent economic factors have affected mathematics performance of girl child and to establish the factors affecting the effectiveness of parents economic being provided to enhance mathematics performance of girl child in secondary schools in Kenya.

This chapter is concerned with the various opinions of different authors, consultants about quality enhancement initiatives and academic performance of girl child in mathematics. The different books, journals, reports, magazines and other literature on the topic of study would were consulted. Marriam (2002) defined quality as the peculiar and essential character. The character is a logical proposition of being affirmative or negative.

The Free Dictionary (2002), defined quality enhancement as to make greater, as in value, effectiveness. Free Online Dictionary (2002), defined initiative as the power or ability to begin or to follow through energetically with a plan or task. It also defines it as the power or right to introduce a new legislative measure. According to ministry of Education Science and Technology final report by Campbell \& Moganees (2005) quality enhancement initiative was 
the effort by the government to improve on academic performance under Universal Primary Education (UPE). According to Wassanga \& Kyalo (2007), quality improvement is a complete process of identifying, describing continuous quality improvement in integration with the rest of initiatives toward enhancing performances. According to Logwe and Kyalo, quality enhancement initiative is an effort with the purpose of improving the quality of mathematics and science education at secondary schools level in Kenya.A great number of definitions for quality enhancement initiatives have been advanced in the literature. Quality enhancement is defined from the term "Quality Assurance". The term quality assurance is a tool used by government to increase, widen or control participation in the rising demand for higher education and a public commodity. It is also fundamental to the security of qualifications and the mobility of professionals (Hejeune, 2004). Armstrong (2009), defines a girl as a female child, from birth to full growth 18 years of age, but unmarried. Armstrong (2009), defines performance as the accomplishment of a given task measured against present known standards of accuracy, completeness, cost and speed. In a contract, performance is deemed to be the fulfillment of an obligation in a manner that releases the performer from all liabilities under contract. Chen, Lee, \& Stevenson (2006) defines performance standards as the knowledge and skills that students are to perform at various stages of educational development and performance expectations for students work at each stage.

Giuseppe Peano (2002), one of the earlier scholars of mathematics defines mathematics as the abstract study of quality, structure, space, changes and many other topics. It has no generally accepted definition. Haskell Curry (2003) defined mathematics simply as "the science of formal systems" A formal system is a set of symbols and some rules telling how the symbols may be combines into formals. To a great extent quality enhancement initiatives and girl child performance in mathematics depend on each other, the two variables rely on each other because quality enhancement initiatives provides the stimulus for girl child performance in mathematics to be realized. Girl child performance mathematics to a greater extent would depend on quality enhancement initiatives that would positive or negative in secondary schools in Kwanza Division. The rationale behind quality enhancement initiatives and girl child performance in mathematics are closely tied up in the framework of relationship. Pizdex \& Menious (2002, findings reveal that after girls are marginalized and given a subordinate status in mathematics class. The findings suggest that perception of teachers are that girls performances in mathematics are dependent on rote learning, handwork and perseverance rather than natural talent, flexibility and risk taking which are learning styles for boys. Opolot \& Okurut (2005) found out that for all the attitudinal variables (anxiety, confidence and motivation), males had higher mean scores than females. Chen, Lee, \& Stevenson (2006) found out that teachers tend to direct more questions at boys than girls. They also believed that girls needed more explaining than boys because girls felt insecure to ask questions when they did not understand. In this study, it stated that the reasons for girls' lack of participation in mathematics classes were that girls were either embarrassed or afraid that their peers (especially boys) would laugh at them.

\section{Theoretical Framework:}

In trying to maximize the accuracy of explanation of the quality enhancement initiatives and girl child performance in mathematics in secondary schools, there is need to thoroughly and critically select the appropriate theories. THERE ARE many QUALITY enhancement theories that can provide an important setting for the study in progress. Account would be made to look at appropriateness of the theories selected for the study. The researcher would identify a selection criteria that would best serve the purpose of the current study, based on the objectives of the study to identify the different quality enhancement initiatives and girl child performance in mathematics, establish the extent to which quality enhancement initiatives have enhanced mathematics performance of girl child and to establish factors affecting the effectiveness of quality enhancement initiatives in enhancing mathematics performance of girl child in secondary schools in Kwanza Division. The theoretical framework for this study was derived from Lewey (2006) on the progressive education or progressive theory, his supporters and critics. According to Dewey's theory knowledge can only be found within ordinary experience, as the individual interacts with his environment. He did not agree with the common belief of the time traditionalism which was authoritarian approach in education, which regarded the teacher as the sole authority in the classroom and which forced the pupils to abide by a rigid system of rules and regulations for purposes of discipline and character formation. This tradition way of thinking violated the psychology of the child as well as the whole idea of democracy. He asserted that children learn by experience, by exploring their environment (quality enhancement initiatives) by the process of inquiry and by putting their ideas to the test. Education in this sense is life itself, according to Dewey and not merely a preparation for life. This can only happen if learning is directly linked to the needs and interest of the child, if education is child-centered. In reaction to traditional authoritarian approach, Dewey suggested an approach that is not teacher centered but child centered, not content centered but method centered. 
Dewey stressed the importance of experience and growth of active inquiry and freedom as well as creativity, these being the key concepts of this educational philosophy (theory). Education carries this to be understood in progressive terms as promoting the individual child's progress. From this concern with progress' has been derived the name given to Dewey's approach, which came to be known as progressive education or as progressivism in contrast to the traditionalism of TRADITION- oriented education in Europe (Eccles \& Harol, 2008). Progressive movement theory Lewey (2006) as it was known became the dominant force in American educational thinking as encouraged by Dewey and his followers. Their united stand against traditionalism provoked in turn, a strong reaction from traditional oriented educationalists. This reaction signaled the beginning of what is now called the great debate in philosophy of education. This debate that continues till today is between the two dominant trends is educational philosophy, between the progressive and traditionalist trends in educational thought. In reaction to Dewey's progressive philosophy of education, the traditionalists proposed two new philosophies of education which become known as essentialism and perennialism. Essentialism reiterated the role of the teacher as the centre of authority in the educational process; it also emphasized the importance of scientific knowledge. The pupil accepts the establishment facts of life as provided by science, on the authority of the teacher. While essentialism acknowledge the progressives concern with scientific progress, perennialism was more radical in reaction and dissociated itself completely from progressive education perennials stressed the perennial or everlasting values of life, which it was urged must be transmitted without change from generation to generation.

A wealth of research has documented differences in the academic achievement of girls and boys Dwyer and Johnson (2009). There is clear evidence that girls outperform boys in terms of their grades in school. This sex differences is evident in stereotypically feminine subject areas such as reading, History and writing. Dwyer and Johnson (2007), Entwisle et all (2009). Moreover, despite stereotypical expectations to the contrary, girls also receive equal or higher grades than boys in stereotypically masculine subject areas, such as mathematics and science Dwyer and Johnson (2007). As in the case of for grades, girls out perform their male counterparts on achievement tests in stereotypically feminine subject areas US Department of Education (2000). However, boys perform better than girls on achievement tests in the stereotypically masculine areas of mathematics and science, although boys have recently cost the edge over girls on achievement tests in mathematics, US Department of Education (2000) and Hyde et al (2000). Theories, research and policies have identified the significant role of families, family- school relations and parental involvement in education, Fan and Chen (2001) and Chao (2009). Family school relations and parental involvement in education have been identified as a way to close gaps in achievement and maximize students' potential, (Dearing, Kneider, Simpkins and Weis 2006). Although research is not entirely consistent, Lylton and Romney (1991), there is evidence indicating that parents more closely monitor girls' progress more than that of boys, current girls' mistakes more than those of boys and make decisions for girls more than they do for boys, (Bumpus, Crouter and Meltale 2001). Parents also see girls performance in mathematics as due to their effort but see boys' performance in this area as due to their abilities, (Eccles, Jacobs and Harold 2000). Such practices and benefits communicate to girls the importance of exerting attention and effort as a way to increase knowledge and understanding. Much of the literature quality enhancement initiatives and girls child performance in mathematics in secondary schools was based in America and Europe. However, the study regarding the quality enhancement initiative and girl child performance in mathematics in Kwanza Division of Kenya will suit the Dewey's theory. The study could be useful and relevant to educationists, policy makers, teachers and students in Kwanza Division, Kenya and the rest of the world.

\section{Quality enhancement affecting performance of girl child:}

Initiative for Educational Equity, American Association of University Women, DC (2002) carried out a research on the girls' performance in mathematics, and observed that teacher may contribute to girls' poor performance by giving them less attention in classes. Therefore teachers should avoid using gender biased practices especially during mathematics instructions. In a study of mathematics performance in different types of secondary schools in Kenya. Eccles \& Harol (2008), found that streaming based on gender improved mathematics achievement and particularly for girls. Hejeune (2004) asserts that gender differences in mathematics are not solely biologically determined, but results from a combination of factors including psychological and environmental. Gill (2004), in her research observed that high school girls have positive attitudes towards mathematics. She rejected authors' belief that separating boys and girls for mathematics lessons improves girls' attitude towards mathematics. Hason \& Katharine (2004) analyses that effective teaching of mathematics to girls and working on their attitude and behavior in mathematics class can improve performance in mathematics. According to Peitilt \& Liza (2005), in her paper came up with the observation that Girls felt that they would be capable of becoming doctors or veterinary doctors, but they did not want to have science related careers as adult boys. Girls never recognized the relationship between 
the study of mathematics and science and their future career aspiration. Garry (2005) indicated that Girls have lower expectation for themselves in mathematics than boys, and that girls behave like they do not have mathematics ability. When girls do poorly in mathematics, they attribute their poor performance to their inability to do mathematics. A review of literature from different studies on gender gaps in achievement by Gallager and Kaufman (2005), concluded that girls score lower than boys on standardized test for mathematics. This argument is supported by the work of Nelson and Brammer (2010), who found that in mathematically intensive fields, women's progress is less dramatic. Zh'u (2007) concludes that the literature has consistently reported that boys do better than girls in standardized mathematics test but only among high ability students. This conclusion is consistence with findings by Garry (2005), who posts that gender gaps in mathematics attainment are largely concentrated amongst the highest achievers.

Drawing from developmental psychology, Campbell \& Moganees (2005) explores the various ways of learning of mathematics among females. He concluded that girls are traditionally denied the opportunity to learn mathematics in a way that they would succeed due to the styles of teaching and learning that are not congruent to how girls approach mathematics tasks. According to Plante et al, one of the contributing factors to gender stereotypes on girls mathematics performance decreased as a function of their female teachers' mathematics anxiety, boys mathematics performance remained unaffected. Research in Australia indicates that gender differences in mathematics achievement are reducing and shifting For Gasz, Leder and Vale (2000). Vale (2009), found that many studies conducted between 2000 and 2004 in Australia showed no significant differences in mathematics between males and females, though males were more likely to obtain higher mean scores.

Extent to which quality enhancement initiatives has affected girl child:

There have been studies that suggest that teachers and schools structure affect the teaching and learning of mathematics to place boys at an advantage (Koelher, 2006). Fennema and Leder (2000) reported that teachers treat male and female students differently and the treatment favors male students. Classroom interaction has emerged as a factor in explaining the gender gap in mathematics, (Jungwith, 2001). These studies have found that boys' use of verbal and non- verbal language tends to command more of the teacher's time in both attention and classroom control. Furthermore, boys are more mobile in the classroom than girls and this tends to influence some teachers beliefs that boys are more competent than girls. Contrary to these findings, Randall (2007) discovered that female students receive more attention from teachers than male students. Headerson (2006) observed that there is a strong relationship between a family background, a student's achievement and education in school and the community. It was found that there is a strong indication between student achievement and the extent to which the family is involved in his or her education. Pexzdekk, Tiffany, \& Reno (2002) examined the effect of parents involvement in mathematics homework of their children increased the accuracy of mathematics skills hence eliminating poor mathematics scores. Participation of both parents and teachers to help with homework was found to increase the depth and quality of learning, (Hatch 2008). The schools mission is to promote the importance of parental involvement and should work on the classroom and school environments to improve children adjustment and engagement, (Simmons Morton and Crump, 2003). Parents should be very much involved in the lives of their early adolescent children, assist them and preparing them for the modern life, (Simmons Morton and Crump 2003).

Effectiveness of quality initiatives and girl child performance:

The most challenging task faces educators today is the quality enhancement initiative in secondary schools, (Eccles \& Harol, 2008). One factor that is influencing performance in mathematics is that most of the parents lack the training to offer continuous involvement with their child's homework, (Cooper \& Robinson, 2004). Recent research has shown that the gender gap in mathematics, perceived to exist between girls and boys is contested in research. This is so in studies undertaken in the African context (Ashcraft \& Faust, 2004). In the present study, it is surprising that there seems to be a gender gap in favor of girls. Girls suggested that they had different learning styles to boys and this placed them at an advantage. Girls liked working with other girls collaboratively to solve mathematics problems and sharing ideas. This is in contrast to Garry (2005), who found that different learning goals of girls and boys leave girls at a disadvantage in competitive environments. Garry (2005) found that girls valued experiences that allowed them to think and develop their own ideas as their aim was to gain understanding. According to Guarrenga \& Kaufman (2005), there is evidence indicating that parents more closely monitor girls progress than that of boys, they correct girl mistakes more than boys and make decision for girls more than they do for boys (Hason \& Katharine, 2004). Parents also see girl performance in mathematics as due to their effort but see boys performance in this area due to their abilities. Eccles \& Harol (2008) in a research on the effects of parents involvement in homework a meta analysis of 14 students showed that training parents to be involved in their child homework result 
in an improvement of homework completion, fewer homework problems and possibly enhanced academic performance among the school children (Cooper \& Robinson, 2004). A report by Headerson (2006) indicated a strong evidence of achievement between student's performance and the extent to which the family is involved in her education. Another factor is parents' personal beliefs about the causes of school achievement and their ability to help their child, (Kenya National examination council, 2011). In most cases parents spend more time watching television than talking about school issues with their children (Chen, Lee, \& Stevenson, 2006). To improve their involvement parents should establish a routine for their child and observe their progress to help in homework completion, (Pollyann \& Onwuegebuzie, 2001).

Many parents advised that they do not receive enough information about school and what is going on at school, (Cleverson 1999). The lack of information can be summarized into concerns surrounding initiation, appropriate, reliability, follow through lack of clarity and usefulness of communication and lack of teacher knowledge of students needs (Nelson, 2010). According to Munk (2001), involvement opportunities to communicate differing attitudes of parents and teachers toward homework and teachers' limited knowledge about the students' strength and needs are factors which cause communication problem. Effective communication requires a two way flow of information, because of that, clear communication between students, parents and teachers is important to show the benefits of homework completion Coutts, (2004). Research suggested different ways for teachers to keep the communication open- ended such as phone calls, e- mail, or a homework hotline (Munk et-al, 2001). This communication should start out at the beginning of the year with the education sharing their homework policy (Heitzmann, 1998). Most schools develop efficient structures for getting information out, but few of them develop similar structures to ensure receiving a feedback. The daily communication and feedback between home and schools is the most widely used or requested service by parent (Campbell \& Moganees, 2005). For some schools improving communication involves technology such as e- mail, messages and interactive phone systems. Using such ways of communication will guarantee clear home/ school communication with parents (Wassanga \& Kyalo, 2007). Tobolka (2006) communicated with parents through the internet. He found that electronic communication enhance students interest in their course work and provide a clear picture for the parents about daily class activities and parents felt more involved in their students school activities and more connected to the teacher. Students increasingly felt that it was important that they turned to their work and homework. They all wanted to have positive notes about their week sent home. Clearly, parent involvement is important to the success of students and communication with parents is essential to support that involvement. The above survey shows however, no specific study has been carried out on quality enhancement initiatives and girl child performance in mathematics in Kwanza District in Kenya, hence the need for the present study.

\section{Conceptual framework:}

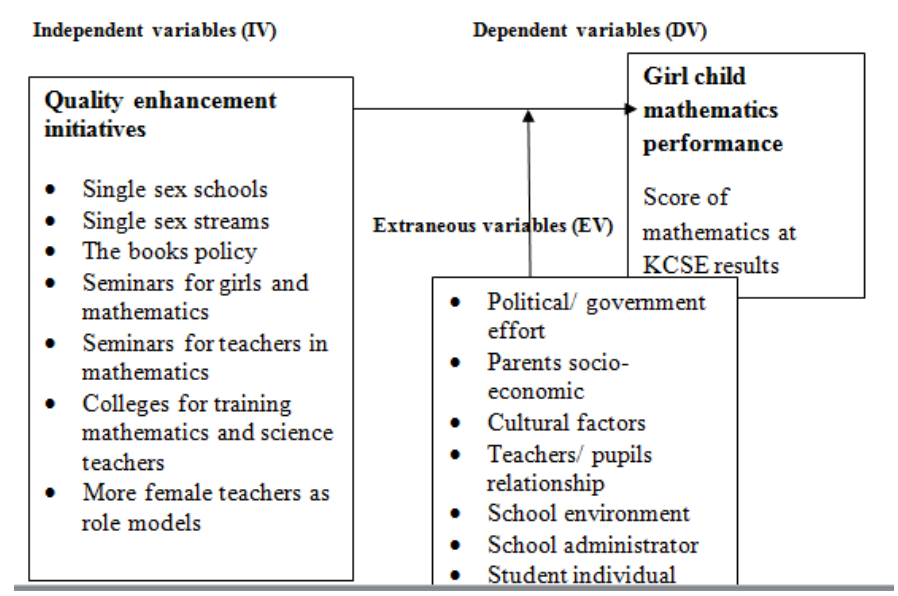

Figure 1:- 2.1: A model showing relationship between quality enhancement initiative (IV) and girl child performance in mathematics in secondary schools (D.V). In the above model quality enhancement initiatives are conceptualized as single sex schools, single sex streams, the book policy, seminars for girls and teachers in mathematics, colleges for training mathematics and science teachers and more female teachers as role models. Girl child mathematics performance on the other hand is conceptualized as KCSE score (C+) in mathematics. The model further hypothesis that quality enhancement initiatives on girls child mathematics performance but the results may 
be confounded by other factors such as political /governmental effort, school environmental, school administrators and students individual personal characteristics, parent economic factors etc, as indicated in the diagram.

\section{Research Methodology And Design:- \\ Research Design:}

The study was non experimental design and was conducted through cross- sectionals survey research design. Data was collected for a short single moment in time and was analyzed to give the results. The researcher investigated population by selecting samples of secondary schools in which the study about quality enhancement initiatives and performance of girls in mathematics in secondary schools in Kwanza Division will be conducted. The schools were selected through stratified sampling techniques. The target population consisted of secondary schools, teachers, head teachers, District Education Officers and form four students in selected schools in Kwanza Division of Trans-Nzoia County in Kenya. The 2013 form four students were targeted because they have been in secondary school for at least three years. For this period of time they had an opportunity to be nurtured by their mathematics teachers to cover the syllabus. They too could give information on how adequate they had being prepared to achieve better grades in mathematics. The mathematics teachers facilitated the teaching process. Head teachers and deputies were included in the target population because they supervised and co-coordinated the implementation of the curriculum in schools. The district education officers were included in the target population because they oversee, monitor and evaluate the implementation of the mathematics curriculum in schools. Kwanza division has 23 secondary schools with 23 head teachers and their deputies and 70 mathematics teachers and 700 form four students. All secondary schools in the division offer mathematics as a compulsory subject for Kenya Certificate of Secondary Examination (KCSE). Thirteen schools were included in the study. The total target population was 700 and therefore the sample size was equivalent to 254 (Krejcie and Morgan 1990). All Head teachers form 4 students, mathematics teachers, District Education Officer were included in the study. The number of students selected from each school varied according to the number of students in form four classes at a ratio of 1:4.

The sample selected was got by calculating as follows:

$\frac{\text { total Number }}{\text { total population }} \mathrm{X}$ sample size

Table 3.1:- population Sample size

\begin{tabular}{|l|l|l|l|l|}
\hline Population section & Target number & Proportion & Sample size & Number selected \\
\hline Form 4 students & 660 & 0.88 & 256 & 225 \\
\hline Mathematics teachers & 65 & 0.087 & 256 & 22 \\
\hline Head teacher & 23 & 0.031 & 256 & 8 \\
\hline DEO & 2 & 0.002 & 256 & 1 \\
\hline Total & 750 & 1 & 256 & 256 \\
\hline
\end{tabular}

There after I improvised four bowls each marked according to stratum names as, form four students, mathematics teachers, Head teachers and DEO. I then wrote all names of population as per stratum on pieces of paper and placed them into the bowls as per their levels for where I drew simple random samples without replacement which I arrived at the sample size of 256 The study employed stratified random sampling, simple random sampling and purposive sampling techniques. Stratified sampling techniques were used to select thirteen secondary schools out of 23 to be studied. Simple random sampling on the other hand was used to select the students, the teaching administration staff.

For selection of the education officers, head teachers and mathematics teachers' purposive techniques was used. Simple random sampling technique selects a sample without bias from the target/ accessible population. Stratified sampling identifies sub- groups in the population and then proportion and select from each sub- group to form a sample. Using purposive technique for researcher will consciously decide who to include in the samples. The researcher is convinced that the target population is not uniform. The students do not necessary have similar characteristics and even the staff in different section within the same school environment and the education office may not think similarly, over a given issue. As such the target and accessible population cannot be regarded as homogenous but heterogeneous. Simple random sampling will ensure that each member of the target population has an equal and independent chance of being included in the sample. Stratified sampling techniques were therefore used to ensure that the target population was divided into different homogenous strata and that each stratum is represented in the sample in a proportion equivalent to its size in the accessible population. This would ensure that each sub- group characteristic was represented in the sample thus raising the external validity of the study. Simple random sampling would ensure that each member of the target population has equal and independent chance of 
being included in the sample. Purposive sampling was used to select teachers, head teachers and district education officers. The study used questionnaires and document analysis guides as the main tools for collecting data. The selection of these tools had been guided by the nature of data to be collected, the time available as well as by the objectives of the study. The overall aim of the study was to determine the quality enhancement initiatives that influence performance of girl child student in mathematics in selected secondary schools in Kwanza division Kenya.

The researcher was mainly concerned with views, opinions perception feelings and attitudes of the respondents concerning quality enhancement initiatives on girl child mathematics performance in secondary schools. A questionnaire was the ideal tool for collecting data. The target population was also literate and was unlikely to have difficulties responding to questionnaire items. Checklists and document analysis guides were also necessary for collection of secondary data on KCSE grades on students' respondents. To control quality the research instruments were pre-tested in order to test and improve on their validity and reliability. The researcher endeavored to attain a content validity and reliability coefficients of at least 0.50 or $50 \%$. The validity index using inter-judge method will be employed. A content validity coefficient or index greater than 0.5 (CVI $>0.5)$ implied that the instruments are valid (Enon. 1998). Validity was determined using content validity index (C.V.I), C.V. $=$ I item rated 3 or 4 by both judges, divided by the total number of items in the questionnaire. This can summarized as

CVI Total No approved $\mathrm{x} 1000$

CVI Total N. set And symbolized as N 3/4 (OSO and Onen, 2008)

Reliability will be measured by the degree to which a research instrument yields consistent results or data after repeated trials. The study was quantitative in nature. Data collected from sample size of 256 out of a target population of 750 . However, the retrieval rate was 254 constituting response rate of $99 \%$ and this was judged sufficient for the analysis. During the months of April to June 2013 questionnaire, checklist and documentary analysis techniques were used. In April 2013, the researcher collected data on student respondents KCSE 2012 results from all participating schools. The data was collected, edited, coded, classified, tabulated and analyzed using SPSS analysis package.

\section{Findings and Discussion:-}

The findings on the opinion of Book policy was well understood in secondary schools as most respondents believed that that factor had strong effect on girl child mathematics performance. Parents being very key players in the learning process of their children they were both as role models, mentors and providers of learning resources especially text books. Governments through free secondary education programmes were to be committed towards this cause. The study revealed that the parents were the best people to build the positive attitude in their girls by providing the necessary teaching/Learning resources to supplement those provided by the schools through teachers.

The study findings revealed that text book policy of 1:1 implementation programme had a significant influence on the mathematics performance of girl child. The study discovered that many schools were not conducting monitoring and benchmarking of schools' performance policy (Nabule Elizabeth and Ezine Enos, 2018), as supported by (Abriant and Odok 2006) who assert that girls had different learning styles to boys and this places them at an advantage. Girls like working with other girls collaboratively to solve mathematics problems and sharing ideas.

Therefore supportive relationship observed in seminars enhances mathematics performance of girl child through motivation. The study findings revealed that quality enhancement initiatives had a significant influence on the mathematics performance of girl child.. The findings also revealed that qualification of teachers had contributed to girl child performance in mathematics. According to Lytton \& Roney (2001), teacher/ pupil relationships through career guidance by the teacher contribute positively to girl child performance in mathematics. The findings on the opinion of availability of teaching/ learning resources most respondents believed that the factor had strong effect on girl child performance in mathematics. Teaching/ learning resources are very key players in the learning process of girl child and all learners. The government and stakeholders in education have to make sure that learning resources are provided through free secondary education (FSE) programmes, free grants, dominations and fund raising. Kiejer and Sekaquaptewa, (2007) asserts that environmental factors have a great influence on the motivation and performance of girl child in mathematics. 


\section{Conclusion and Recommendations:-}

The study from the findings concluded that since mathematics was a key subject that controls all the human entities was to be taught in discriminatively to all students irrespective of the physically being of an individual. Due to this, it came up with the following recommendations:

1. The principals should reinforce the mathematics departments in their schools to have a practical approach in teaching to make it participatory,

2. The school should encourage peer teaching of mathematics

3. Female parents, teachers and stakeholders who have excelled in mathematics should organize regular talks to the girl child.

4. The school should organize regular seminars at all levels in mathematics and girls schools should organize regular mathematics contexts where Parents are encouraged to provide adequate teaching/ learning mathematics resources.

5. The school leadership (Principal, Board of Governors, Parents, teachers, BOG Association, (PTA), and sponsors should sensitize parents on the need to help change students attitude towards mathematics, whereby Schools leadership should organize for regular resource people role model talk to girl child about mathematics performance.

\section{References:-}

1. Ashcraft, M. H., \& Faust, M. W. (2004). Mathematics Anxiety and Mental Arithmetic performance. new York: Cognition and Edmonton publishers.

2. Campbell, P., \& Moganees, P. (2005). Role of parents in education fo children. New York: University of NewYork.

3. Chen, Lee, \& Stevenson. (2006). Parents' involvement in students' education. Johannesberg:JohannesbergPublishers.

4. Cooper, S. E., \& Robinson, D. A. (2004). The influence of gender and anxiety on mathematics performance. London: College Development Group.

5. Eccles, E., \& Harol, G. (2008). Abilities of boys in mathematics performance. Nairobi: Kenyatta mandatory publishers.

6. Garry, D. (2005). Mathematics scores out fo Anxiety. Nairobi: based international writers.

7. Gill, J. (2004). Varying attitudes towards Mathematics. Kampala: makere University.

8. Guarrenga, L., \& kaufman, H. (2005). Level of excellence in Mathematics for boys and Girls. Nairobi: ITC Embarkee.

9. Hason, \& Katharine. (2004). Effectiev teaching mechanisms. Edmonton: Edmonton cennter of acdemic excellence.

10. Jungwith. (2001). Explaining teh gender gap in mathematics. Delhi : DHS Rserves.

11. Kenya National examination council. (2011). level of Mathematics aPerfromance by girls in Eastern Africa. Nairobi: University fo Nairobi-examination Department.

12. Kiefer, \& Sekaquaptewa. (2007). Mathematics as a perceives challenge for females in the world. new Delhi: delhi Academic Center.

13. Koelher. (2006). Effects of teaching and learning Mathematics. Nairobi.

14. Krejce, \& morgan. (1970). Guide for Determining Appropriate sample sizes for a study population. London: London publishers.

15. Lavree, D., \& Kelsvre, R. (2008). How Hoem language aids transition to western culture. New York: Massecute College of Intellectuals.

16. Maddi, C., \& KObasa, L. (2001). Assessment fo students' cscores in Mathematics. NewYork: Nwk Publishers.

17. Mado, L., \& Kobassa, F. (2002). Relationship between individual scores and mathematics anxiety. New York: newYork times.

18. Meinholt, \& Murray. (2009). Female students can demonstrate their academic efforts in relation to their male counterparts given chance. New York: University of New York.

19. Nelson, B. (2010). Mathematically related fields of excellence. London: london Times.

20. Peitilt, \& Liza. (2005). Observation of Girls' feelings on Mathematics. New delhi.

21. Pexzdekk, Tiffany, B., \& Reno, P. A. (2002). Children's Mathematics Achievement: The role of parents' perceptiona nd tehir involvement. Educational psychological institute.

22. Pizdex, M., \& Menious, D. (2002). Parennt awareness on their children'smathematics achievement. Jarcata: Jarcata VSD. 
23. Pollyann, M., \& Onwuegebuzie, F. (2001). Gender difference in reading and Mathematics. Newjersey: N.I.T Printeries.

24. Samilre, R., \& kongsh, C. (2005). variations in mathematics performance across countries. Pretoria: Center of Academic excellence. 